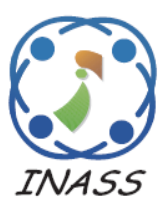

\title{
Reconfigurable a Dual-Port Multi-Band Antenna System with High Isolation Tuning Characteristics for Portable Wireless Devices
}

\author{
Malik Jasim Farhan $^{1^{*}}$ \\ ${ }^{I}$ Electrical Engineering Department, Mustansiriyah University, Baghdad, Iraq \\ * Corresponding author's Email: malik.jasim@uomustansirizah.edu.iq
}

\begin{abstract}
In modern wireless and portable devices, reconfigurable antennas could be utilized to operate across many frequency bands and scan radiation patterns according to user requirements. This paper presents a low-profile planar multiple-input multiple-output (MIMO) antenna system-based frequency-reconfigurable multi-band with high isolation and pattern diversity properties. It applies to various wireless technologies, including UMTS, LTE, WiMAX, Bluetooth, Wi-Fi, and sub- $6 \mathrm{GHz}$. The MIMO arrangement uses two identical antenna elements that are symmetrically arranged and cover an overall size of $45 \times 65 \times 1.6 \mathrm{~mm}^{3}$ while also providing frequency shifting and pattern reconfigurability. The proposed antenna functions in four distinct modes, depending on the state of the two lumped element switches per radiator, and so operates at eleven different frequencies: 2.2, 2.4, 2.8, 3.2, 3.3, 3.4, 3.5, 5.2, 5.3, 5.4 , and $5.5 \mathrm{GHz}$, which are reserved for practical wireless applications (3G/4G/sub-6 GHz). The antenna's impedance bandwidth is between 9 to $30.28 \%$, while its peak gain and efficiency range between 1.8 to $3.26 \mathrm{dBi}$ and 42 to $75.4 \%$, respectively, depending on the mode of operation. The antenna scattering and far-field characteristics are determined numerically using a technique known as Finite Integration (FIT) in Computer Simulation Technology (CST). The measured results agree with the simulated results, confirming the antenna's frequency and pattern diversity capability for portable wireless devices.
\end{abstract}

Keywords: Reconfigurable antennas, MIMO antenna, Pattern diversity, Sub-6 GHz, Multi-band antenna.

\section{Introduction}

The advancement of wireless communication devices in recent years necessitates integrating multiple applications into a single device. This can be accomplished by combining numerous antennas into a single device or by combining a single antenna with various functions into a single device. Due to their adaptable performance, reconfigurable antennas of multi-mode designs have piqued the interest of numerous academics. Most current circuits employ reconfigurable antennas to optimize size, power consumption, and bandwidth [1] simultaneously. On the other hand, because all recent wireless communications require very dependable high-datarate systems, multiple-input-multiple-output (MIMO) technology has been implemented [2]. Reconfigurability can be accomplished optically, electrically, or mechanically using specific materials such as liquid crystals. Mechanical reconfigurable antenna systems, on the other hand, have a complicated and bulky configuration. As a result, researchers are more interested in electrically reconfigurable antennas, which are simpler to fabricate and require less complexity. Numerous studies have published multiple reconfigurable antenna mechanisms throughout the last decade [313]. [3] Describes the use of liquid metal to achieve reconfigurability in a frequency-reconfigurable patch antenna operating in the Industrial Scientific and Medical (ISM)/Global Positioning System (GPS) band. In [4], by integrating the antenna with a bias network, Radio Frequency Micro-electromechanical Systems (RF-MEMS) switches are utilized to switch at a quicker pace with dual-frequency reconfigurable bands $(4.57$ and $4.88 \mathrm{GHz})$. Electrically adjusted plasma is used to reconfigure low-profile broadband plasma antennas for VHF and UHF applications [5]. 
$[6,7]$ Investigated and produced frequency-agile antennas based on metamaterial elements. [8] Use RF PIN diodes to achieve reconfigurability across nine different frequency bands. The antenna described in [9] incorporated an epsilon negative transmission line to achieve frequency reconfigurable features, which was advantageous for GSM and WLAN applications. Eight varactor diodes are employed to implement reconfigurability in [10], which runs between 1.64 and $2.12 \mathrm{GHz}$.

In [11], a collection of optical (photoelectric) switches is used to reconfigure the frequency and radiation using millimetre-wave frequencies of 28 and $38 \mathrm{GHz}$. Five PIN diodes on the substrate's top surface, along with four parasitic elements and an electric-inductive-capacitive (ELC) resonator encased in a closed ring resonator (CRR), are used to radiate bi-directional and unidirectional end-fire radiation at different frequencies [12]. Three PIN diodes are used as a switching device in the planer antenna [13] to provide reconfigurability for sub-6 GHz $5 \mathrm{G}$ bands $(2.1,2.4,3.6$, and $5.2 \mathrm{GHz})$ with an expanded use for Wireless Local Area Network (WLAN). The stated references [3- 13] incorporate additional bands into the same antenna, complicating antenna design $[14,15]$. As a result, such frequencyreconfigurable MIMO antenna systems are an excellent solution for meeting the high-rate data requirements of modern wireless technologies due to their ability to operate in MIMO mode while reconfiguring their operating frequency in response to system demands. Recently, various MIMO antenna designs for dual-band WLAN applications $[16,17]$ and WiMAX applications [18, 19] have been published. Techniques described in these papers have non-planar structures and are unsuitable for tiny planar portable devices with different band operations. Only a few multi-bands MIMO antenna systems are practical for incorporating a small USB dongle [20, 21]. These designs, however, do not perform well in isolation or with polarization/pattern diversity in different bands. Additionally, the compact size requirement for multi-band MIMO antenna system design limits the decoupling circuits' space. Therefore, the decoupling circuitry must provide excellent isolation in both working bands [22]. Numerous Decoupling Circuit (DC) designs have been described in the literature [21, 23-25]. According to Reference [25], the reconfigurable multi-ports necessitates a reconfigurable DC. As a result, designing a small DC that provides high isolation between the multi-band reconfigurable MIMO antenna's two states is a complicated issue.

On the other hand, the literature has described multiple frequency reconfigurable MIMO antenna designs [25-28]. However, as mentioned earlier, all proposals and designs are substantial in space, making them incompatible with portable wireless devices with small form factors. Additionally, the previous works result in the system's complexity due to the physical modification of the antenna structure, which exhibits a large size, poor isolation, and lower bandwidth of multi-bands. Nevertheless, these characteristics are necessary for highly dependable, multi-standard, and reliable wireless communication systems in the future.

As a result, the proposed system in this study is a planner multi-band frequency reconfigurable MIMO U-shape etched patch antenna design with pattern diversity capabilities that are well suited for portable wireless devices-the suggested system is packed on a single board and can operate in seven bands. The frequency reconfiguration of the MIMO antenna is accomplished by including a PIN-diode for each radiator; this enables the MIMO antenna to convert from mode-1 (switches On): 2.7-3 GHz, 3.1-3.9 GHz, and 5.1-5.6 GHz to mode-2 (switches Off): $2.5-3.9$ $\mathrm{GHz}$ and 5.1-5.6 GHz and from mode-3 (Off-On): 2.35-2.51 GHz, 2.7-3.97 GHz to mode 4 (On-Off): 2.1-2.3 GHz, 2.9-3.96 GHz. Switching the MIMO antenna between modes requires no changes to the existing decoupling circuit, greatly simplifying the overall design. The presented design is minimal, fitting within a $45 \times 65 \times 1.6 \mathrm{~mm}^{3}$ board volume. This design is also notable for its planar architecture and wide-range frequency switching through PIN diodes. The design accomplishes a frequency-tunable band between the lower and upper bands and eleven distinct frequencies: 2.2, 2.4, 2.8, 3.2, 3.3, 3.4, 3.5, 5.2, 5.3, 5.4, and $5.5 \mathrm{GHz}$, which support mainstream $3 \mathrm{G} / 4 \mathrm{G}$ and sub-6 standards. Furthermore, the adoption of a Rectangular Defective Ground Structure (RDGS) enhances isolation between closely located antennas.

The following matters are presented in this paper: Section 2 defines the methodology of MIMO antenna design, while section 3 shows the switching and resonant mode for each configuration. Sections 4 and 5 present the defective ground structures and performance of the MIMO antenna system. A comparison with the referenced antennas is provided in section 6. The conclusion is finally stated in Section 7.

\section{Methodology of antenna design}

The dual-port frequency reconfigurable MIMO antenna system illustrated in Fig. 1 can adjust both isolation characteristics and operational frequency 


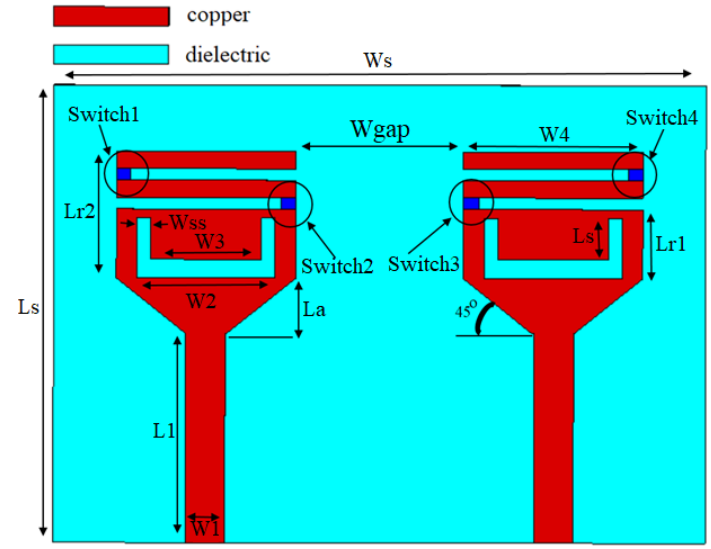

(a)

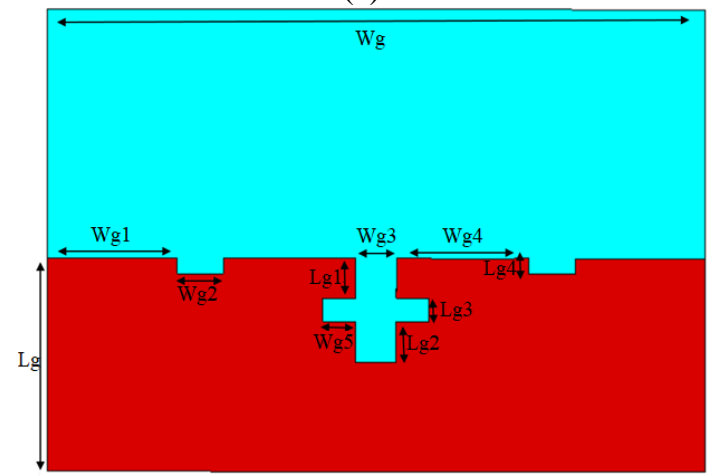

(b)

Figure. 1 Dual-port Antenna: (a) top view, (b) bottom view

bands simultaneously. The proposed configuration's U-shape slot patch antenna and ground are implemented on an FR-4 substrate with a 4.4 relative permittivity, a loss tangent of 0.0025 , and a thickness of $1.6 \mathrm{~mm}$. The system ground plane dimensions 45 x $65 \mathrm{~mm}^{2}$ in total, considering the physical area constraints associated with Personal Digital Assistance (PDA) or portable device applications. The conventional transmission line theory creates a 50-ohm microstrip feedline with a width $=3 \mathrm{~mm}$ [29]. The following formulae serve as a starting point for basic antenna dimension calculations that are then utilized to build and model the antenna.

The length of the antenna patch is specified as follows [29]:

$$
\begin{gathered}
L=\frac{1}{2 f_{r} \sqrt{\mu_{0} \varepsilon_{0}} \sqrt{\varepsilon_{\text {reff }}}}-2 \Delta L \\
\varepsilon_{\text {reff }}=\frac{\varepsilon_{r}+1}{2}+\frac{\varepsilon_{r}-1}{2}\left[1+12 \frac{h}{W}\right]^{\frac{-1}{2}} \\
\Delta L=0.412 h \frac{\left(\varepsilon_{\text {reff }}+0.3\right)\left(\frac{w}{h}+0.264\right)}{\left(\varepsilon_{\text {reff }}-0.258\right)\left(\frac{w}{h}+0.8\right)}
\end{gathered}
$$

Where $\mathrm{L}$ denotes the length, $f_{r}$ represents the resonant frequency, $\varepsilon_{r}$ defines the relative permittivity, $\varepsilon_{\text {reff }}$ means the effective permittivity whose formula is described in Eq. (2). $\Delta L$ Denotes the total length as indicated by Eq. (3).

The width of a patch is calculated as follows:

$$
W=\frac{1}{2 f_{r} \sqrt{\mu_{0} \varepsilon_{0}}} \sqrt{\frac{2}{\varepsilon_{r}+1}}
$$

The width of the feed line is computed as follows:

$$
\frac{w_{\text {feed }}}{h}=\frac{8 \exp (A)}{\exp (2 A)-2}
$$

Where $w_{\text {feed }}:$ width of the feed line, h: thickness of the substrate, and A: determined by the following equation:

$$
A=\frac{Z_{c}}{60}\left\{\frac{\varepsilon_{r}+1}{2}\right\}^{0.5}+\frac{\varepsilon_{r}-1}{\varepsilon_{r}+1}\left\{0.23+\frac{0.11}{\varepsilon_{r}}\right\}
$$

To avoid affecting antenna performance, the simulation predicts that the length of the U-shaped slot is large enough that the entire length may be etched on the radiator while still preserving antenna performance. This results in the creation of triple bands that can be controlled using two switches. Table 1 list the dimensions of the proposed antenna.

\section{Switching and resonant modes}

As illustrated in Fig. 1 (a), the MIMO antenna composed of two symmetrically identical frequency reconfigurable U-slot radiators (antennas 1 and 2), each with two PIN-diodes. The presented reconfigurable design incorporates a primary radiator, an additional radiator on an FR4 substrate, a capacitive load beneath the additional radiator, and

Table 1. Dimensions of the proposed reconfigurable antenna

\begin{tabular}{|c|c|c|c|}
\hline Parameter & $\begin{array}{c}\text { Value } \\
(\mathbf{m m})\end{array}$ & Parameter & $\begin{array}{c}\text { Value } \\
(\mathbf{m m})\end{array}$ \\
\hline$L_{s}$ & 45 & $W_{s}$ & 65 \\
\hline$L_{1}$ & 21.8 & $W_{1}$ & 3 \\
\hline$L_{a}$ & 5.7 & $W_{2}$ & 14.4 \\
\hline$L_{r 1}$ & 7.25 & $W_{3}$ & 11.5 \\
\hline$L_{r 2}$ & 13.25 & $W_{4}$ & 18.7 \\
\hline$L_{g}$ & 22 & $W_{g a p}$ & 17.4 \\
\hline$L_{g 1}$ & 4.1 & $W_{s s}$ & 1.4 \\
\hline$L_{g 2}$ & 4.1 & $W_{g}$ & 68 \\
\hline$L_{g 3}$ & 2.4 & $W_{g 2}$ & 3.8 \\
\hline$L_{g 4}$ & 1.6 & $W_{g 3}$ & 4.2 \\
\hline$L_{s s}$ & 4.32 & $W_{g 4}$ & 3.4 \\
\hline$W_{g 1}$ & 13.4 & $W_{g 5}$ & 12.2 \\
\hline
\end{tabular}



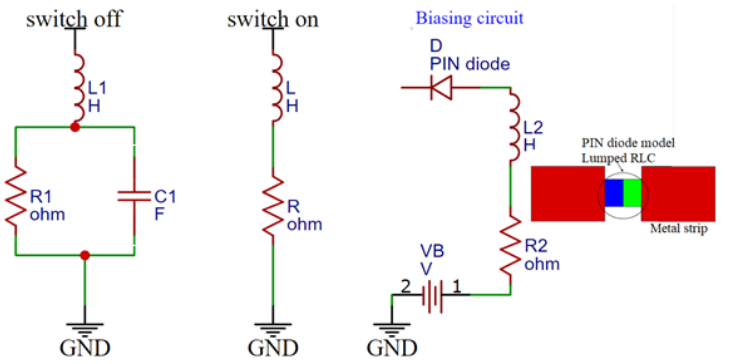

Figure. 2 Equivalent circuit for the OFF/ON state and biasing circuit

two PIN-diodes. By changing the two PIN-diodes, the patch U-slot shape can be adjusted to one of four bands. Generally, the PIN-diode functions as a variable resistor at $\mathrm{RF}$ frequencies, but the $\mathrm{ON}$ and OFF states contain more complicated circuitry. Fig. 2 illustrates the equivalent circuit for the OFF and ON state of the PIN-diode, which consist of a resistor (R), an inductor (L), and a capacitor (C). When the resistor and inductor are linked in series, the diode is biased forward. When the inductor is not in use, it connects to a parallel connected capacitor and resistor. PIN-diode OFF/ON behaviour is investigated using RLC and RL circuit, respectively [30]. The lower Rvalue in the RL circuit allows current to flow between the radiating elements. Conversely, the higher RCvalue in the RLC circuit prevents current from flowing between the radiating portions. Thus, we treated our PIN-diode in the simulation as an RL circuit for the sake of simplicity. The L-value is maintained constant. The $\mathrm{R}$-value is kept as high as 5 $\mathrm{M} \Omega$ when the diode is in the OFF state, while the ON state is kept as low as $1 \Omega$. For the OFF and ON state of the switch, a biasing voltage $\mathrm{VB}$ of $0 \mathrm{~V}$ and $5 \mathrm{~V}$ is given to the circuits, respectively.

Therefore, frequency reconfigurability is accomplished by varying each PIN diode's ON and OFF states, exhibiting open/short circuit behaviour between radiator elements. The radiator shown has four operational modes, each with its resonant frequencies, as illustrated in Fig. 3 (a-d). To achieve Mode 1 (sw1 on and sw2 on), an antenna stimulated with a microstrip feedline was constructed to span the upper-frequency band (5.1-5.6 GHz) with the lowest possible return loss $(-14 \mathrm{~dB})$ at $5.4 \mathrm{GHz}$. The feedline linked to the patch radiator covers the frequency range $3.1-3.9 \mathrm{GHz}$ with a return loss of $(-26 \mathrm{~dB})$ at 3.4 GHz. The patch was etched in a U-slotted shape to improve bandwidth and impedance matching for the second resonant band. At $2.8 \mathrm{GHz}$, a parasitic patch with two stubs was inserted and cascaded with the primary radiator to cover the third band (2.7-3 $\mathrm{GHz}$ ). For Mode 2 (sw1 and sw2 deactivated), the tuning of the lower frequency range of mode 1 was

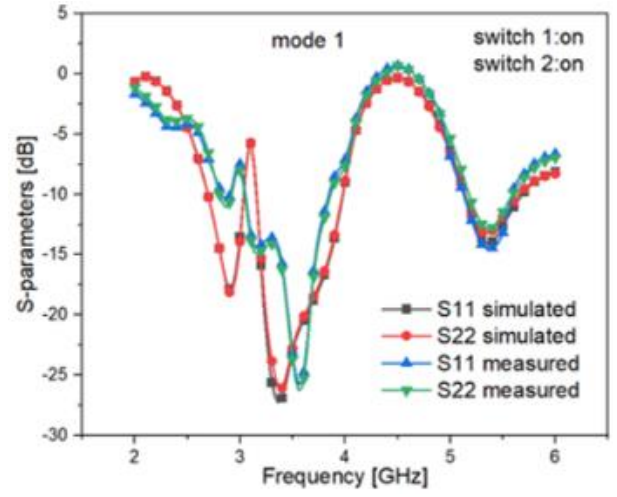

(a)

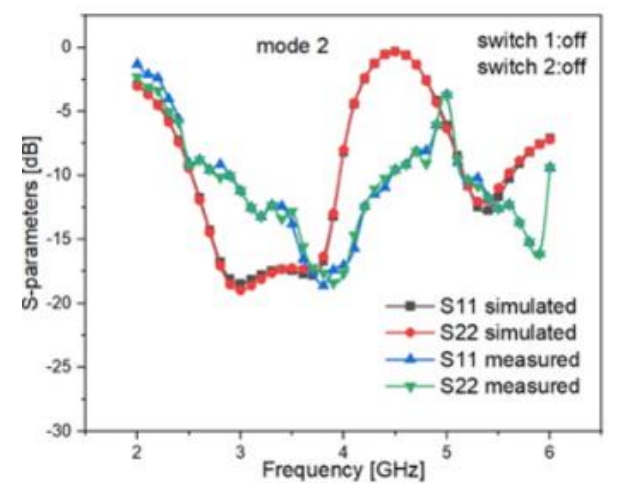

(b)

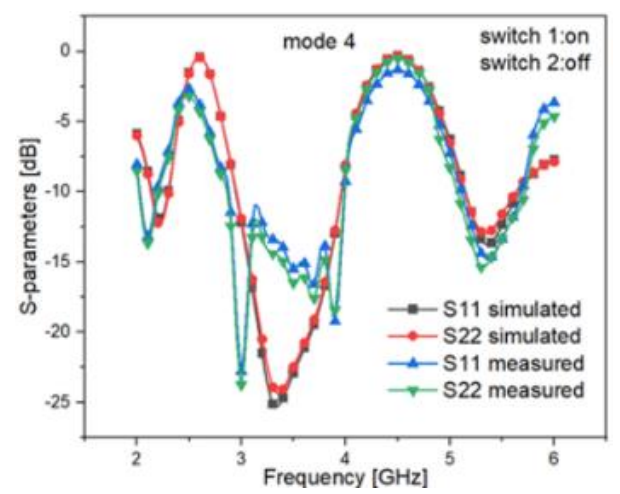

(c)

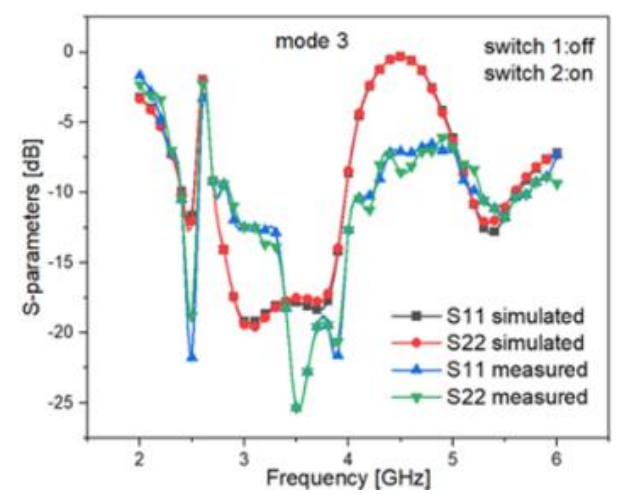

(d)

Figure. 3 Resonant frequencies for a quad-mode: (a) mode 1 , (b) mode 2, (c) mode 3 and (d) mode 4 
Table 2. Modes of tuning antenna bands.

\begin{tabular}{|c|c|c|c|}
\hline $\begin{array}{c}\text { Mode } \\
\text { No. }\end{array}$ & Sw1 & Sw2 & $\begin{array}{c}\text { Frequency Bands } \\
(\mathbf{G H z})\end{array}$ \\
\hline 1 & On & On & $\begin{array}{c}\text { Triple band(2.7-3)(3.1- } \\
3.9)(5.1-5.6)\end{array}$ \\
\hline 2 & Off & Off & $\begin{array}{c}\text { Dual band(2.5-3.9)(5.1- } \\
5.6)\end{array}$ \\
\hline 3 & Off & On & $\begin{array}{c}\text { Triple band(2.35- } \\
2.51)(2.7-3.97)(5.1-5.6)\end{array}$ \\
\hline 4 & On & Off & $\begin{array}{c}\text { Triple band(2.1- } \\
2.3)(2.9-3.96)(5.1-5.6)\end{array}$ \\
\hline
\end{tabular}

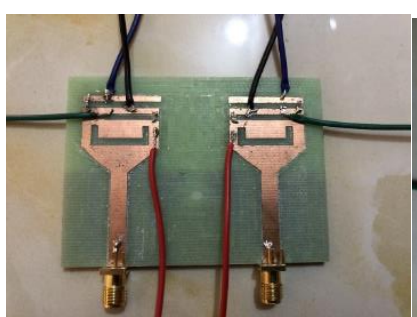

(a)

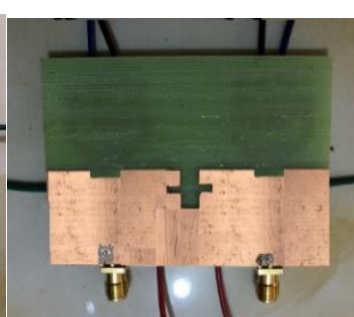

(b)
Figure. 4 Antenna fabrication prototype: (a) top view and (b) bottom view

The top and bottom of the fabricated antenna are shown in Fig. 4. The antenna is constructed using a low-capacitance PIN diode, SMP 1345-040LF (Skyworks), and a DC path is entirely disconnected from the feeding path. Using a KC901-V Vector Network Analyzer (VNA) tool, the reflection coefficient of the fabricated prototype is determined. This tool calibrated by the short-open and loadthrough (SOLT) technique. After calibration, it is linked to the constructed prototype, and the return losses are determined. Fig. 3 illustrates the simulated and measured results for the four operational modes: The proposed antenna exhibits exceptional frequency reconfigurability and operates in nine bands with only two diodes per radiator.

\section{Decoupling by the defected ground}

The term "decoupling by the defective ground structures" refers to the process of etching periodic or non-periodic features into the antenna's ground. These geometries exhibit band stop filtering properties, modifying the characteristics of microwave transmission to enable decoupling design. Decoupling via defective ground structures (DGS) can be used in a variety of antenna configurations, including microstrip patch antennas [31], PIFA antennas [32], and UWB antennas [33]. Moreover, numerous DGS types, such as fractal [34] and symmetric structures [35]. As illustrated in Fig. 1(b), a meandered slot is etched into the ground between the antennas to eliminate mutual interaction between

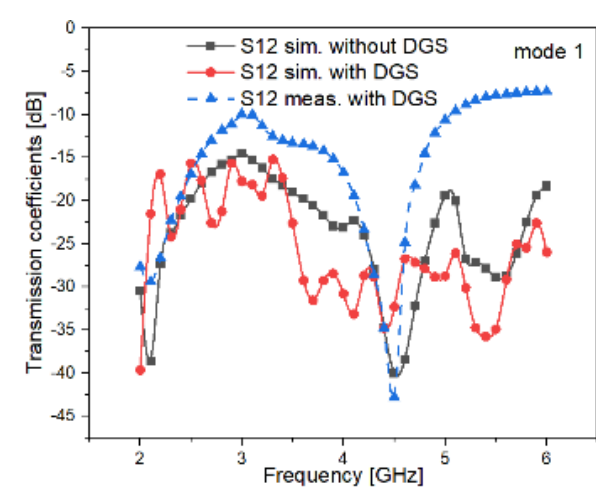

(a)

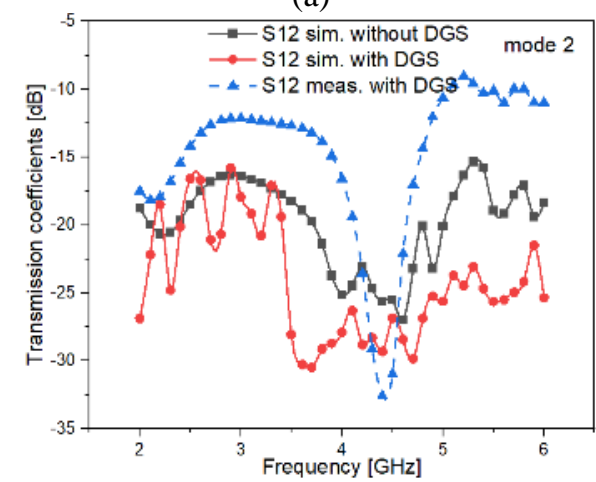

(b)

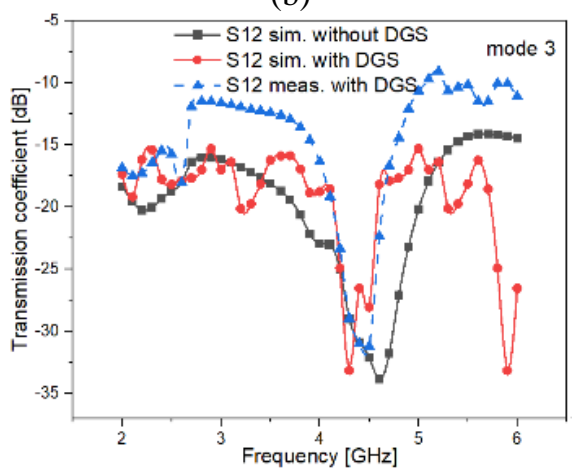

(c)

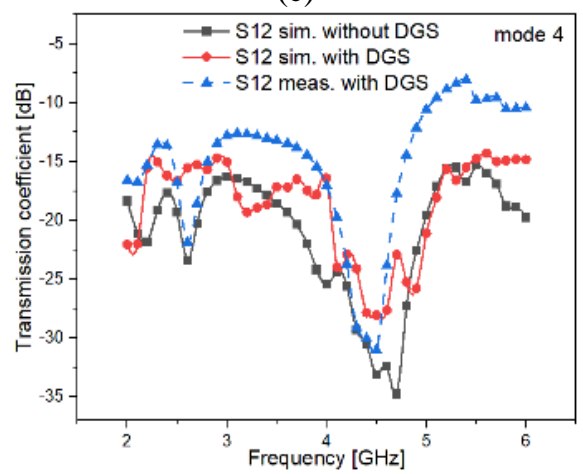

(d)

Figure. 5 Port-to-port isolation: (a) mode 1, (b) mode 2, (c) mode 3, and (d) mode 4

them. As observed in Fig. 5, the antenna isolation (transmission coefficients) can be enhanced to greater than $-15 \mathrm{~dB}$ in the intended frequency spectrum by etching the ground. The DGS-based decoupling technique is a simple structure and effective way to increase the isolation between the 
ports. However, due to the resonance characteristics, the DGS will change the antenna's radiation properties.

Additionally, the DGS requires a specific amount of antenna volume, which is incompatible with a miniaturized design. Without the slot-line isolator, the MIMO antenna achieves port-to-port isolation values of less than $-10 \mathrm{~dB}$ for all operational modes, as indicated by the dashed lines in Fig. 5, which should be improved. An etching is placed into the ground plane's centre to reduce mutual coupling and achieve the required good isolation across a wide range of multi-bands, as illustrated in Fig. 1 (b).

\section{Performance of proposed reconfigurable MIMO antenna}

The reconfigurable antenna's MIMO performance is evaluated in terms of Envelope Correlation Coefficient (ECC), Diversity Gain (DG), and Multiplexing Efficiency. ECC determines the mutual connectivity and degree of correlation between radiators. It is computed using S-parameters by Eq. (7), which is valid for determining ECC when the radiated power is spread uniformly, and the antenna is lossless [29].

$$
\rho_{e}=\frac{\left|S_{i i}^{*} S_{i j}+S_{j i}^{*} S_{j j}\right|^{2}}{\left(1-\left|S_{i i}\right|^{2}-\left|S_{j i}\right|^{2}\right)\left(1-\left|S_{j j}\right|^{2}-\left|S_{i j}\right|^{2}\right)}
$$

Where $S_{i j}$ : is the coupling factor between $\mathrm{i}^{\text {th }}$ and $\mathrm{j}^{\text {th }}$ elements and $\rho_{e}$ : is the ECC.

However, because lossless is a theoretical result that differs from empirical results, the ECC of the MIMO antenna is computed using Eq. (8) in terms of electric fields.

$$
\rho_{e}=\frac{\left|\iint_{4 \pi}\left[E_{i}(\theta, \phi) \times E_{j}(\theta, \phi)\right] d \Omega\right|^{2}}{\iint_{4 \pi}\left|E_{i}(\theta, \phi)\right|^{2} d \Omega \times \iint_{4 \pi}\left|E_{j}(\theta, \phi)\right|^{2} d \Omega}
$$

Where $E_{i}$ and $E_{j}$ are the radiated electric field vectors of the $\mathrm{i}^{\text {th }}$ and $\mathrm{j}^{\text {th }}$ elements of the MIMO system respectively, and $\Omega$ signify beam area.

While uncorrelated MIMO antennas have an ideal ECC value of zero [36], their practical value is less than 0.5. As illustrated in Fig. 6 (a), the ECC of proposed MIMO antennas is less than 0.01 in the lower and upper bands. As a result, the mutual coupling between the dual-ports is relatively low, indicating a good diversity performance. The DG may be determined using the formula $D G=10 \times$ $\sqrt{\left(1-\rho_{e}^{2}\right)}$, and for the MIMO antenna to operate

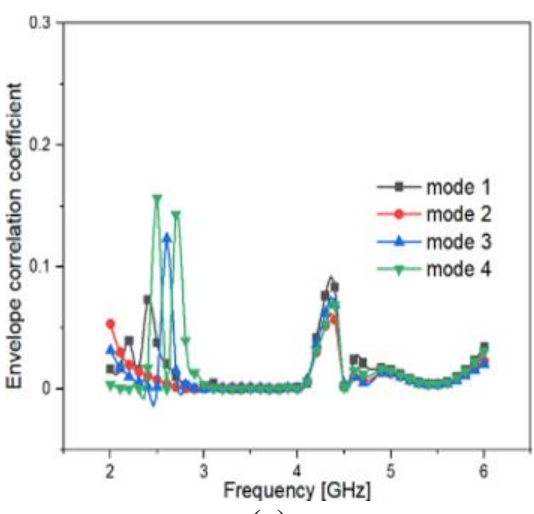

(a)

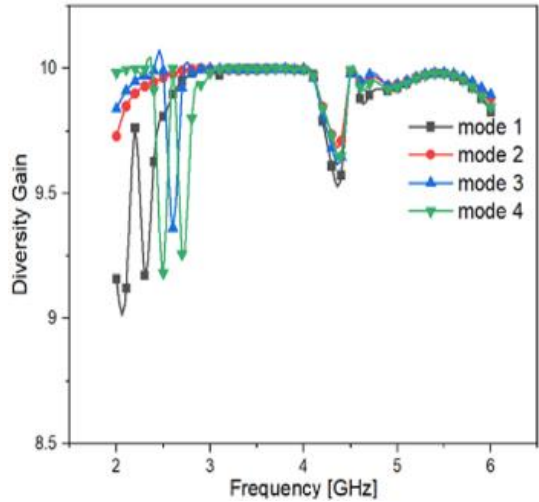

(b)

Figure. 6 MIMO Ant. performance: (a) ECC and (b) DG

satisfactorily, the diversity gain should be less than $10 \mathrm{~dB}$. The DG of the MIMO antenna is $9.97 \mathrm{~dB}$ in the targeted bands, as illustrated in Fig. 6 (b).

Additionally, the antenna's performance is determined by examining the efficiency and gain of the various elements over their respective operating bands. Table 3 illustrates the antenna's simulated gain and efficiency in four different cases. As observed, the antenna has a good gain and a good efficiency in four distinct configurations.

\subsection{Far-field radiation pattern}

Fig. 7 illustrates the co-polarizing component (Ephi) and cross-polarizing component (E-theta) farfield radiation pattern of the proposed MIMO antenna in the XY and YZ planes of various modes. As depicted, Ants. 1-2 has complimentary radiation characteristics in the XY plane and broadside phi, polarized radiation patterns. In addition, Fig. 7 indicates that the antenna elements' radiation beams are angled in opposing directions (i.e., $-45^{\circ}$ and $+45^{\circ}$ ).

The E-phi component is $15-18 \mathrm{~dB}$ in the direction of the main lobe at frequencies of quadratic modes bigger than the comparable cross-polarizing component (E-theta). The results indicate that the antenna radiates adequately in both E-planes when 


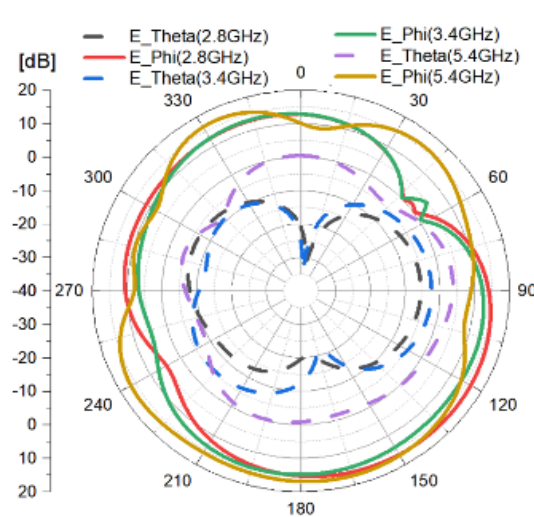

(a)

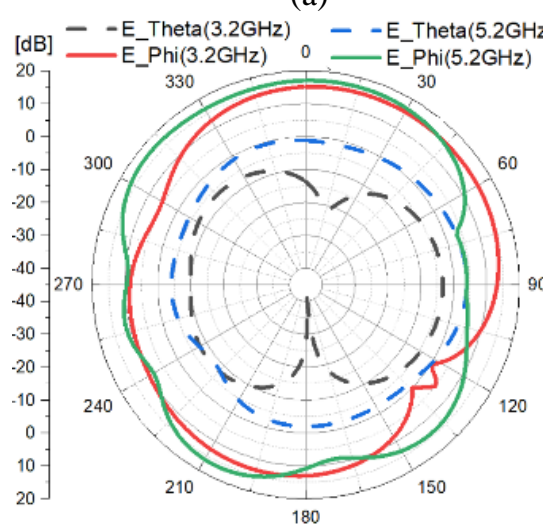

(d)

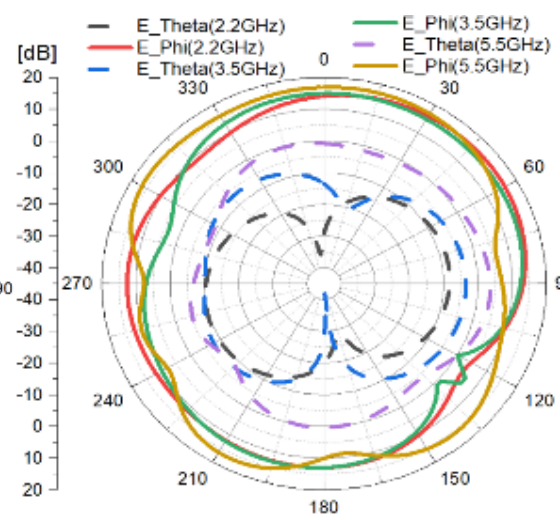

(b)
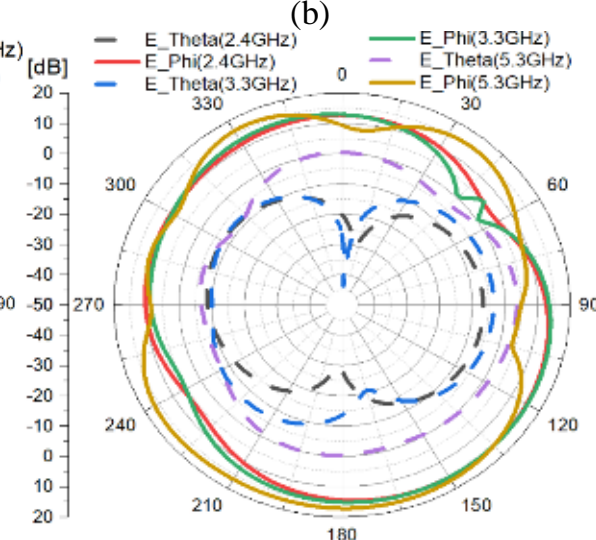

(e)

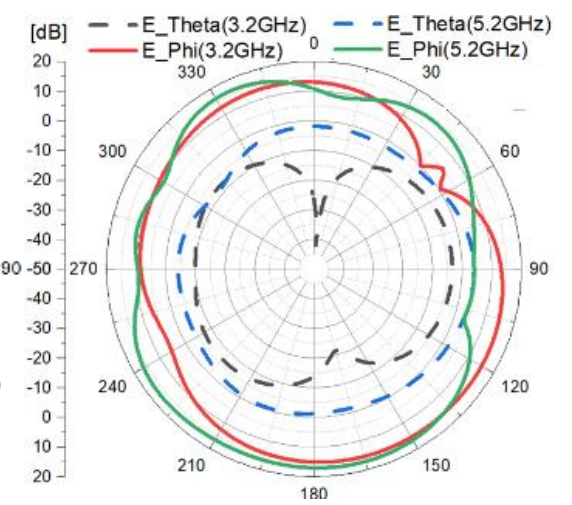

(c)

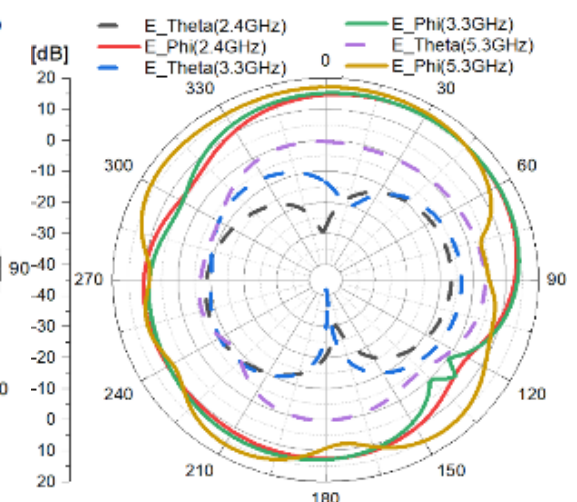

(f)

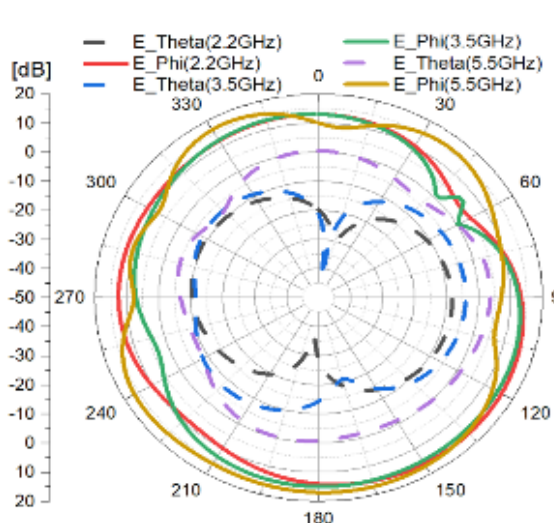

(g)

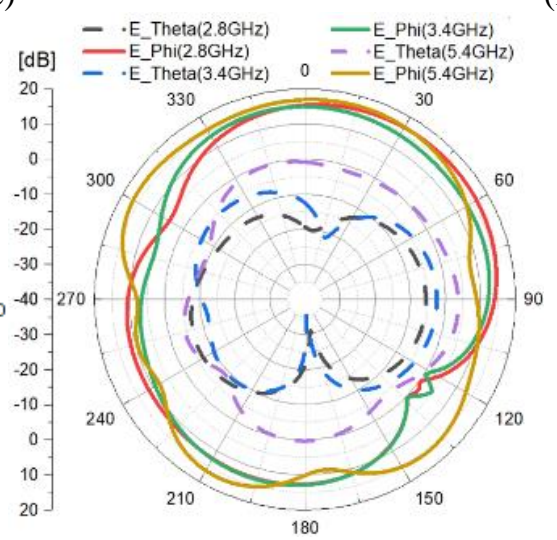

(h)

Figure. 7 Quad-mode Far-field radiation pattern for E-theta and E-phi: (a-b) mode 1 (Ant.1-2), (c-d) mode 2(Ant.1-2), (ef) mode 3 (Ant.1-2), and (g-h) mode 4 (Ant.1-2)

co-polarized. While in the cross-polarization condition, the electric field is predominantly negative, the radiation in the plane is exceedingly weak.

The tilt in the radiation pattern for various switching modes of PIN-diodes is shown in Table 3. As observed, the radiation pattern in the different modes is tilted between 24 and 175 degrees in the $\mathrm{YZ}$ plane and between 155-272 degrees in the XZ plane. It illustrates the direction change of the main lobe at $\mathrm{Phi}=90$ for the same frequency in various switching modes.

\subsection{Electric energy density}

Fig. 8 illustrates the distribution of electric energy density on the antenna's radiating structure throughout a range of frequency bands. For Mode 1, the antenna operates on a tri-band $(2.8,3.4$, and 5.5 $\mathrm{GHz}$ ), with the second slot, feed line, and U-slot contributing to radiation at $2.8,3.4$, and $5.5 \mathrm{GHz}$, respectively.

Low concentrations of energy are observed at low frequencies, while higher concentrations of power are detected at higher frequencies. In Mode 2, the energy density indicates a decrease in the radiation wavelength, which results in operating at $3.2 \mathrm{GHz}$ and 5.2GHz. In modes 3 and 4, tri-band operations are 


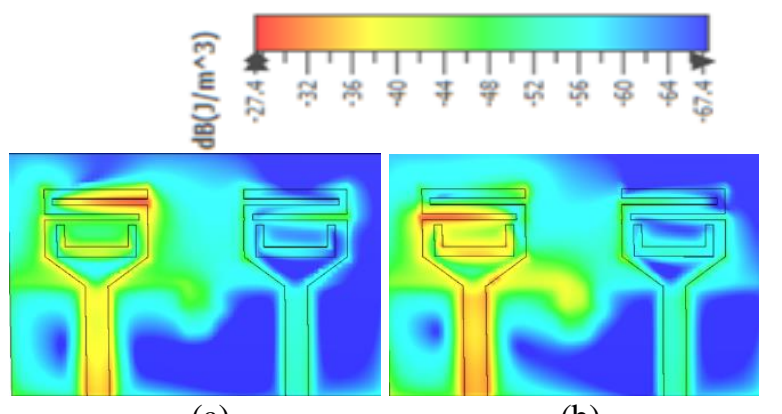

(a)

(b)

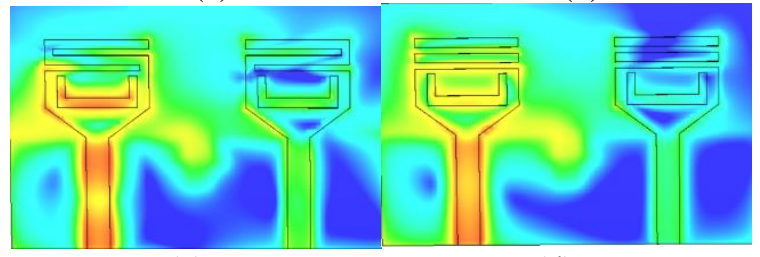

(c)

(d)

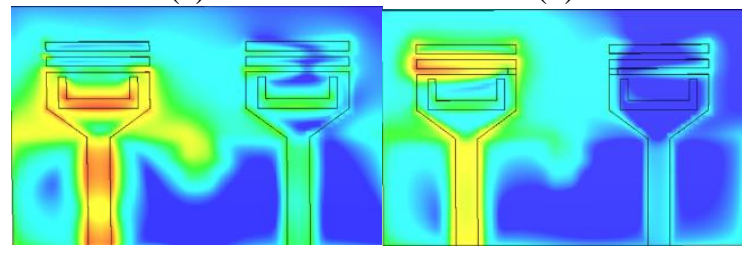

(e)

(f)

Figure. 8 Distribution of electric energy density for a dual-port four modes: (a-c) mode $1(2.8,3.4,5.4 \mathrm{GHz})$, (d-e) mode 2 and $3(3.2,5.2 \mathrm{GHz})$, and (f) mode 4 (2.4 $\mathrm{GHz})$

Table. 3 Antenna gain and efficiency of quad-mode

\begin{tabular}{|c|c|c|c|c|c|}
\hline Mode & $\begin{array}{l}\text { Freq. } \\
\text { [GHz] }\end{array}$ & $\begin{array}{c}\text { Peak } \\
\text { gain } \\
\text { (dbi) }\end{array}$ & $\begin{array}{l}\text { Eff. } \\
{[\%]}\end{array}$ & theta & phi \\
\hline on - on & $\begin{array}{c}2.8,3.4 \\
5.4\end{array}$ & $\begin{array}{c}1.8,3, \\
3.1\end{array}$ & $\begin{array}{c}64, \\
67.8, \\
44.9\end{array}$ & $\begin{array}{c}155 \\
163, \\
24\end{array}$ & $\begin{array}{l}162, \\
190, \\
268\end{array}$ \\
\hline off- off & $3.2,5.2$ & $\begin{array}{l}2.72, \\
2.44\end{array}$ & $\begin{array}{c}66.5 \\
42\end{array}$ & $\begin{array}{c}163 \\
29\end{array}$ & $\begin{array}{l}180, \\
273\end{array}$ \\
\hline off - on & $\begin{array}{c}2.4,3.3 \\
5.3\end{array}$ & $\begin{array}{c}2.46, \\
2.6,2.5\end{array}$ & $\begin{array}{c}75.4 \\
65.8 \\
42\end{array}$ & $\begin{array}{c}171 \\
162, \\
29\end{array}$ & $\begin{array}{l}155, \\
178, \\
272\end{array}$ \\
\hline on - off & $\begin{array}{c}2.2,3.5 \\
5.5\end{array}$ & $\begin{array}{r}1.9,3 \text {, } \\
3.26\end{array}$ & $\begin{array}{c}73.6, \\
67, \\
45.6\end{array}$ & $\begin{array}{r}175, \\
163, \\
25\end{array}$ & $\begin{array}{c}245, \\
193, \\
268\end{array}$ \\
\hline
\end{tabular}

achieved; the energy density indicates the dominant contribution of a more significant portion of radiator for the upper band and a smaller amount of radiator for the lower bands. These electric densities demonstrate that when the resonant frequency increases, the contributing resonant length decreases, establishing the inverse relationship between frequency and resonant length.

\section{Comparison with previously works}

Table 4 summarizes the proposed antenna in comparison to recently designed antennas that are available in the literature. This comparison demonstrates that the stated antenna provides an adequate number of diodes and gain in its reconfigurable frequency ranges while remaining smaller in size than the antennas presented in $[14,23$, 26]. The antenna described in [27] is small and efficient; it has a quad-band frequency response and a low gain. In comparison to [25-27], the suggested U-shape slot antenna exhibits good MIMO performance in terms of isolation, ECC, and gain. The most significant differences from other candidate antennas are the proposed antenna's ability to function on many bands, which exceeds the number of bands obtained in all previously published research.

\section{Conclusion}

In this paper, a compact printed MIMO antenna multi-band with frequency shifting and high isolation capabilities is effectively implemented and experimentally confirmed. The elements are switchdependent and exhibit a wide range of performance characteristics in both the $\mathrm{ON}$ and OFF modes of switches. By including the frequency-reconfigurable capability, the multi-band MIMO antenna's design is made even more compact and well-suited for wireless portable devices that use several standards (UMTS, LTE, WiMAX, Bluetooth, Wi-Fi, and Sub-6 GHz). Two PIN diodes are incorporated into each radiator to enable the proposed MIMO antenna to be reconfigured from mode-1 to mode-4. High isolation is achieved through ground plane etching that reduces the transmission coefficient to less than $-15 \mathrm{~dB}$ and $18 \mathrm{~dB}$ for the lower and upper bands, respectively. Diversity performance is achieved by an antenna that has an ECC of 0.01 , DG of $>9.89 \mathrm{~dB}$, a gain of 1.8 to $3.26 \mathrm{dBi}$, and radiation efficiency of 42 to $75.4 \%$. When the proposed and specified antennas are compared, it is clear that the proposed antenna has a substantially smaller dimension and superior performance characteristics. Additionally, the dualport antenna has a nearly constant radiation pattern with a good gain, which meets $3 \mathrm{G} / 4 \mathrm{G}$ and Sub-6 $\mathrm{GHz}$ applications requirements.

\section{Conflicts of Interest}

The author declares that there is no conflict of interest.

\section{Author Contributions}

M. Jasim devised the idea, the main conceptual ideas and proof outline. M. Jasim was involved in planning and supervised the work. Processed the 
Table 4. Performance comparison with previous published works

\begin{tabular}{|c|c|c|c|c|c|c|c|c|}
\hline \multirow[b]{2}{*}{ Ref. } & \multirow{2}{*}{$\begin{array}{c}\text { Operating } \\
\text { Bands } \\
\text { (GHz) }\end{array}$} & \multirow[b]{2}{*}{$\begin{array}{l}\text { No. of } \\
\text { Ant. }\end{array}$} & \multirow[b]{2}{*}{$\begin{array}{l}\text { Total Size } \\
\left(\mathrm{mm}^{2}\right)\end{array}$} & \multirow[b]{2}{*}{$\begin{array}{c}\text { Diodes } \\
\text { per } \\
\text { Ant. }\end{array}$} & \multicolumn{4}{|c|}{ MIMO performance } \\
\hline & & & & & $\begin{array}{c}\text { Isolation } \\
\text { (dB) }\end{array}$ & ECC & $\begin{array}{l}\text { Gain } \\
\text { (dBi) }\end{array}$ & Eff. \\
\hline$[14]$ & $\begin{array}{c}0.7-0.78, \\
0.79-0.86, \\
2.5-2.69,\end{array}$ & 2 & $200 \times 260$ & 2 & $<20$ & $<0.016$ & --- & $51-80$ \\
\hline [23] & $\begin{array}{l}2.4-2.5 \\
5.2-5.5 \\
3.2-3.7\end{array}$ & 2 & $80 \times 40$ & 2 & $<20$ & $<0.02$ & $1.8-3.8$ & $59-75$ \\
\hline$[25]$ & $\begin{array}{c}5-6, \\
2.39-2.48, \\
5.2-6.4\end{array}$ & 4 & $40 \times 20$ & 4 & $\begin{array}{l}<14.5(\mathrm{LB}) \\
<18(\mathrm{UB})\end{array}$ & $<0.03$ & $\begin{array}{l}-0.5- \\
3.14\end{array}$ & $55-85$ \\
\hline [26] & $\begin{array}{l}1.17-2.4 \\
0.95-2.4\end{array}$ & 4 & $65 \times 120$ & 2 & $<12$ & $<0.018$ & $-0.7-3.5$ & $34-78$ \\
\hline [27] & $\begin{array}{c}3.1-3.8, \\
5.1-5.9, \\
5-5.7 \\
3.4-3.65\end{array}$ & 2 & $48.5 \times 25$ & 2 & $\begin{array}{l}<15(\mathrm{LB}) \\
<17(\mathrm{UB})\end{array}$ & -- & $2.2-3$ & $84-86$ \\
\hline [28] & $\begin{array}{c}1.6-2.48 \\
3.4-3.8 \\
\end{array}$ & 8 & $120 \times 60$ & 1 & $\begin{array}{l}<10 \text { (LB) } \\
<15 \text { (UB) }\end{array}$ & $<0.08$ & $1.7-3.5$ & 67 \\
\hline $\begin{array}{c}\text { Proposed } \\
\text { design }\end{array}$ & $\begin{array}{l}2.7-3,3.1- \\
3.9,5.1- \\
5.6, \\
2.5-3.9, \\
2.35-2.51, \\
2.7-3.97, \\
2.1-2.3, \\
2.9-3.96\end{array}$ & 2 & $45 \times 65$ & 2 & $\begin{array}{l}<-15(\mathrm{LB}) \\
<-18(\mathrm{UB})\end{array}$ & $<0.01$ & $1.8-3.26$ & $\begin{array}{l}42- \\
75.4\end{array}$ \\
\hline
\end{tabular}

experimental data, performed the analysis with CST and ADS software, drafted the manuscript and manufactured the prototype and characterized them with 2-port vector network analyzer. M. Jasim aided in interpreting the results and worked on the manuscript.

\section{Acknowledgments}

The author would like to thanks Mustansiriyah University (www.uomustansiriyha.edu.iq) Baghdad, Iraq for its support in the present work.

\section{References}

[1] J. Costantine, Y. Tawk, S. E. Barbin, and C. G. Christodoulou, "Reconfigurable Antennas: Design and Applications", Proceedings of the IEEE, Vol. 103, No. 3, pp. 424-437, 2015.

[2] W. Hong, Z. H. Jiang, C. Yu, J. Zhou, P. Chen, Z. Yu, H. Zhang, B. Yang, and X. Pang, "Multibeam Antenna Technologies for 5G Wireless Communications", IEEE Transactions on Antennas and Propagation, Vol. 65, No. 12, pp. 6231-6249, Dec. 2017.

[3] M. Gallo, E. A. Daviu, M. F. Bataller, M.
Bozzetti, J. M. M. G. Pardo, and L. J. Liacer, “A Broadband Pattern Diversity Annular Slot Antenna", IEEE Transactions on Antennas and Propagation, Vol. 60, No. 3, pp. 1596-1600, 2012.

[4] T. Aboufoul, C. Parini, X. Chen, and A. Alomainy, "Pattern-Reconfigurable Planar Circular Ultra-Wideband Monopole Antenna", IEEE Transactions on Antennas and Propagation, Vol. 61, No. 10, pp. 4973-4980, 2013.

[5] S. K. Sharma, F. Fideles, and A. Kalikond, "Planar Yagi-UDA Antenna with Reconfigurable Radiation Patterns", Microwave and Optical Technology Letters, Vol. 55, No. 12, pp. 2946-2952, 2013.

[6] H. Cheribi, H. Kimouche, and F. Ghanem, "Metamaterial-based frequency reconfigurable antenna", Electronics Letters, Vol. 49, No. 5, pp. 315-316, 2013.

[7] M. I. Hossain, M. R. I. Faruque, M. T. Islam, and M. T. Ali, "Design and analysis of coupledresonator reconfigurable antenna", Applied Physics A, Vol. 122, No. 2, 2016.

[8] H. A. Majid, M. K. A. Rahim, M. R. Hamid, and 
M. F. Ismail, "Frequency and Pattern Reconfigurable Slot Antenna", IEEE Transactions on Antennas and Propagation, Vol. 62, No. 10, pp. 5339-5343, 2014.

[9] U. Nasir, A. S. Afzal, B. Ijaz, K. S. Alimgeer, M. F. Shafique, and M. S. Khan, "A compact frequency reconfigurable CPS-like metamaterial inspired antenna", Microwave and Optical Technology Letters, Vol. 59, No. 3, 596-601, 2017.

[10] Y. P. Selvam, M. Kanagasabai, M. G. N. Alsath, S. Velan, S. Kingsly, S. Subbaraj, and Y. V. R. Rao, "A low profile pattern and frequency reconfigurable", IEEE Antennas and Wireless Propagation Letters, Vol. 16, 3047-3050, 2017.

[11] M. S. Khan, A. Iftikhar, A. D. Capobianco, R. M. Shubair, and B. Ijaz, "Pattern and frequency reconfiguration of patch antenna using PIN diodes", Microwave and Optical Technology Letters, Vol. 59, No. 9, pp. 2180-2185, 2017.

[12] G. Singh, B. Kanaujia, V. Pandey, D. Gangwar, and S. Kumar, "Pattern and frequency reconfigurable antenna with diode loaded ELC resonator", International Journal of Microwave and Wireless Technologies, Vol. 12, No. 2, pp. 163-175, 2020.

[13] I. Ahmad, H. Dildar, W. Ur, S. Ullah, M. A. Albreem, M. H. Alsharif, and P. Uthansakul, "Frequency reconfigurable antenna for multi standard wireless and mobile communication systems", Computers, Materials \& Continua, Vol. 68, No. 2, pp. 2563-2578, 2021.

[14] B. Mun, C. Jung, M. Park, and B. Lee, "A Compact Frequency-Reconfigurable Multiband LTE MIMO Antenna for Laptop Applications", IEEE Antennas and Wireless Propagation Letters, Vol. 13, pp. 1389-1392, 2014.

[15] W. Hu, L. Qian, L. Wen, X. Yang, and Y. Yin, "Compact dual-band antenna based on CRLHTL for WWAN/LTE terminal applications", International Journal of $R F$ and Microwave Computer-Aided Engineering, Vol. 29, pp. 1-8, 2019.

[16] J. Liang, J. Hong, J. Zhao, and W. Wu, "DualBand Dual-Polarized Compact Log-Periodic Dipole Array for MIMO WLAN Applications", IEEE Antennas and Wireless Propagation Letters, Vol. 14, pp. 751-754, 2015.

[17] H. Chou and H. Su, "Dual-Band Hybrid Antenna Structure With Spatial Diversity for DTV and WLAN Applications" IEEE Transactions on Antennas and Propagation, Vol. 65, No. 9, pp. 4850-4853, 2017.

[18] A. A. Khan, M. H. Jamaluddin, S. Aqeel, J. Nasir, J. R. Kazim, and O. Owais, "Dual-band
MIMO dielectric resonator antenna for WiMAX/WLAN applications", IET Microwaves, Antennas \& Propagation, Vol. 11, No. 1, pp. 113-120, 2017.

[19] A. Boukarkar, X. Q. Lin, Y. Jiang, L. Y. Nie, P. Mei, and Y. Q. Yu, "A Miniaturized Extremely Close-Spaced Four-Element Dual-Band MIMO Antenna System With Polarization and Pattern Diversity", IEEE Antennas and Wireless Propagation Letters, Vol. 17, No. 1, pp. 134-137, 2018.

[20] M. S. Khan, M. F. Shafique, A. Naqvi, A. Capobianco, B. Ijaz, and B. D. Braaten, "A Miniaturized Dual-Band MIMO Antenna for WLAN Applications", IEEE Antennas and Wireless Propagation Letters, Vol. 14, pp. 958961, 2015.

[21] S. M. Wang, L. T. Hwang, F. S. Chang, C. J. Lee, and C. Y. Hsu, "MIMO antenna design with built-in decoupling mechanism for WLAN dualband applications", Electronics Letters, Vol. 51, No. 13, pp. 966-968, 2015.

[22] J. Xun, L. Shi, W. Liu, G. Liu, and S. Chen, "Compact Dual-Band Decoupling Structure for Improving Mutual Coupling of Closely Placed PIFAs", IEEE Antennas and Wireless Propagation Letters, Vol. 16, pp. 1985-1989, 2017.

[23] Z. J. Jin, J. H. Lim, and T. Y. Yun, "Frequency reconfigurable multiple-input multiple-output antenna with high isolation", IET Microwaves, Antennas \& Propagation, Vol. 6, No. 10, pp. 1095-1101, 2012.

[24] D. Sipal, M. P. Abegaonkar, and S. K. Koul, "Compact band-notched UWB antenna for MIMO applications in portable wireless devices", Microwave and Optical Technology Letters, Vol. 58, No. 6, pp. 1390-1394, 2016.

[25] S. Soltani, P. Lotfi, and R. D. Murch, "A Port and Frequency Reconfigurable MIMO Slot Antenna for WLAN Applications", IEEE Transactions on Antennas and Propagation, Vol. 64, No. 4, pp. 1209-1217, 2016.

[26] R. Hussain and M. S. Sharawi, "Planar meandered-F-shaped 4-element reconfigurable multiple-input-multiple-output antenna system with isolation enhancement for cognitive radio platforms", IET Microwaves, Antennas \& Propagation, Vol. 10, No. 1, pp. 45-52, 2016.

[27] N. V. Shahmirzadi and H. Oraizi, "Design of reconfigurable coplanar waveguide-fed planar antenna for multiband multi-input-multi-output applications", IET Microwaves, Antennas \& Propagation, Vol. 10, No. 14, pp. 1591-1597.

[28] S. Riaz and X. Zhao, "An Eight-Port Frequency 
Reconfigurable MIMO Slot Antenna with Multi-Band Tuning Characteristics", In: Proc. of International Symposium on Antennas, Propagation and EM Theory, Hangzhou, China, pp. 1-4, 2018.

[29] C. A. Balanis, Antenna Theory: Analysis and Design, John Wiley \& Sons, 2016.

[30] I. Yeom, J. Choi, S. Kwoun, B. Lee, and C. Jung, "Analysis of RF Front-End Performance of Reconfigurable Antennas with RF Switches in the Far Field", International Journal of Antennas and Propagation, Vol. 2014, pp. 1-14, 2014.

[31] J. O. Yang, F. Yang, and Z. M. Wang, "Reducing Mutual Coupling of Closely Spaced Microstrip MIMO Antennas for WLAN Application", IEEE Antennas and Wireless Propagation Letters, Vol. 10, pp. 310-313, 2011.

[32] S. Zhang, B. K. Lau, Y. Tan, Z. Ying, and S. He, "Mutual Coupling Reduction of Two PIFAs with a T-Shape Slot Impedance Transformer for MIMO Mobile Terminals", IEEE Transactions on Antennas and Propagation, Vol. 60, No. 3, pp. 1521-1531, 2012.

[33] Q. Li, A. P. Feresidis, M. Mavridou, and P. S. Hall, "Miniaturized Double-Layer EBG Structures for Broadband Mutual Coupling Reduction Between UWB Monopoles", IEEE Transactions on Antennas and Propagation, Vol. 63, No. 3, pp. 1168-1171, 2015.

[34] K. Wei, J. Li, L. Wang, Z. Xing, and R. Xu, "Mutual Coupling Reduction by Novel Fractal Defected Ground Structure Bandgap Filter", IEEE Transactions on Antennas and Propagation, Vol. 64, No. 10, pp. 4328-4335, 2016.

[35] C. Chiu, F. Xu, S. Shen, and R. D. Murch, "Mutual Coupling Reduction of Rotationally Symmetric Multiport Antennas", IEEE Transactions on Antennas and Propagation, Vol. 66, No. 10, pp. 5013-5021, 2018.

[36] Q. H. Kareem and M. J. Farhan, "Design a Linear and Circular Polarization MIMO Antennas Based on Compact Size Configurations with High Isolation and Stable Gain Characteristics for C- Band and WLAN / WiMAX Applications", International Journal of Intelligent Engineering and Systems, Vol. 14, No. 3, pp. 458-467, 2021. 